\title{
ARTIGOS
}

\section{TRANSFORMAÇÃO GLOBAL DA ENERGIA: A PARTICIPAÇÃO DAS ENERGIAS RENOVÁVEIS NA MATRIZ ELETRICA DAS 50 MAIORES ECONOMIAS}

GLOBAL ENERGY TRANSFORMATION: THE PARTICIPATION OF RENEWABLE ENERGY IN THE 50 LARGEST ECONOMY ELECTRICAL MATRIX

MATHEUS FERNANDO MORO, M.SC. |UFSC

ANNY KEY MENDONÇA, Dra. | UFSC

GABRIEL DE ANDRADE CONRADI BARNI, M.SC. |UFSC

ANTONIO CEZAR BORNIA, Dr. | UFSC

\begin{abstract}
RESUMO
Diferentes países têm adotado políticas para a redução da emissão de $\mathrm{CO} 2$, um dos principais fatores no impacto climático e ambiental. Com base nisso, o objetivo desta pesquisa foi investigar a relação entre o PIB, consumo de energia, participação de energias renováveis e as emissões de $\mathrm{CO} 2$ per capita das 50 maiores economias do mundo, para o período de 1990 a 2015. Realizou-se a correlação de Pearson entre as variáveis e uma análise de cluster para verificar o perfil dos países que possuem similaridades, ao longo do tempo, na participação de energias renováveis em sua matriz elétrica. Os resultados encontrados sugerem correlação positiva, de moderada a forte, entre crescimento econômico e consumo de energia e correlação negativa, de fraca a moderada, entre participação de energias renováveis na matriz elétrica dos países e emissão de $\mathrm{CO} 2$. A análise de cluster separou os países em três grupos, sendo o primeiro deles aquele que mais possui energia renovável em sua matriz elétrica, composto por países como Brasil, Canadá e Noruega.
\end{abstract}

PALAVRAS CHAVE: Matriz elétrica; energias renováveis; emissão de CO2

\begin{abstract}
Different countries have adopted policies to reduce $\mathrm{CO} 2$ emissions, one of the main factors in climate and environmental impact. Based on this, the objective of this research was to investigate the relationship between GDP, energy consumption, renewable energy and CO2 emissions per capita of the 50 largest economies in the world, from 1990 to 2015. It was using a Pearson's correlation between the variables and a cluster analysis to verify the profile of countries that have similarities over time in the participation of renewable energies in their electrical matrix. The results suggest a moderate to strong positive correlation between economic growth and energy consumption and a weak to moderate negative correlation between the participation of renewable energies in the countries' electric matrix and $\mathrm{CO} 2$ emissions. The cluster analysis separated the countries into three groups, the first one having the most renewable energy in its electric matrix, composed by countries such as Brazil, Canada and Norway.
\end{abstract}

KEY WORDS: Electrical matrix; renewable energy; $\mathrm{CO} 2$ emission 


\section{INTRODUÇÃO}

A eletricidade é essencial para a redução da pobreza, crescimento econômico e para a melhoria da qualidade de vida, mas sua geração não tem sido renovável (WORLDBANK, 2019). Passados quase dois séculos do início da revolução industrial, muitos países ainda baseiam sua geração de energia por meio de combustíveis fósseis, como carvão, petróleo e gás-natural, os quais produzem Dióxido de Carbono (CO2) e outros gases que provocam as mudanças climáticas globais (SAMPEDRO et al., 2017; BROZYNA et al., 2019).

Em 2015, o mundo consumiu 149.790 terawatt-hora (TWh) por ano de energia primária, aproximadamente $52 \%$ a mais do que em 1990 (WORLDBANK, 2019). Todo esse consumo de energia levou a um rápido aumento nas emissões de $\mathrm{CO} 2$, causando impacto no aquecimento global. O aquecimento global e as mudanças climáticas provocam impactos ecológicos e climáticos extremos, como as secas, tempestades, inundações, elevação do nível do mar, ondas de calor, crescimento alterado na agricultura, bem como impactos à saúde da população e pobreza (LIN; AHMAD, 2017; LIN; RAZA, 2019).

Os efeitos prejudiciais que as emissões de $\mathrm{CO} 2$ estão transmitindo ao planeta são bem reconhecidos (MEROUEH; CHEN, 2020) e representam a principal preocupação por parte do setor energético, no que se refere ao aquecimento global.Deacordo com a Avaliação do Painel Intergovernamental sobre Mudanças Climáticas (IPCC) (AR5), os gases de efeito estufa, em particular as emissões $\mathrm{CO} 2$, provenientes das atividades humanas, têm sido a principal causa da aceleração do aquecimento global (IPCC, 2014a).

A relação entre crescimento econômico e consumo de energia, assim como crescimento econômico e poluição, tem sido objeto de diversas pesquisas nos últimos anos. Os resultados dessas pesquisas podem desempenhar um papel significativo para compreender como o crescimento da renda e da população poderão afetar as emissões no futuro.

Apesar de muitos estudos abordarem as questões entre Produto Interno Bruto (PIB), consumo de energia e emissões de $\mathrm{CO} 2$, poucos trabalhos relacionam essas variáveis com a participação de Energias Renováveis (ER) na matriz elétrica dos países. Sabe-se que a energia não renovável contribue para as emissões de CO2 (ADAMS; NSIAH, 2019), entretanto há questionamento sobre a utilização de energia renovável e sua relação com as emissões de $\mathrm{CO} 2$. Ainda assim, a urbanização em países da África e Ásia, aumento da população e a industrialização da economia possuem relação com o incremento das emissões de $\mathrm{CO} 2$ no planeta.

Nesta pesquisa, a relação entre o PIB, consumo de energia, participação de energias renováveis e as emissões de $\mathrm{CO} 2$ per capita das 50 maiores economias do mundo foi investigada para o período de 1990 a 2015 Desse modo, a pesquisa está norteada por três questionamentos: i) há relação entre PIB per capita e consumo de energia per capita?; ii) há relação entre emissões de $\mathrm{CO} 2$ per capita e participação de energia renovável na matriz elétrica?; e iii) há semelhança entre as matrizes elétricas dos países em relação a produção de energia renovável?

\section{PRODUÇÃO DE ENERGIA ELÉTRICA DAS 50 MAIORES ECONOMIAS DO MUNDO}

Um dos desafios mais importantes que a humanidade enfrenta, e certamente o mais complexo de solucionar, é a descarbonização do setor energético (KERN; ROGGE, 2016; AHMAN et al., 2017; SCHELLNHUBER et al., 2018). As perspectivas de descarbonização do setor aumentaram nas últimas décadas, com o desenvolvimento e o crescimento do mercado de potenciais tecnologias de emissão zero, como a energia eólica, a solar fotovoltaica, os biocombustíveis, os sistemas de transporte elétrico e os edifícios de energia zero (IPCC, 2014b; AHMAN et al., 2017). A descarbonização pressupõe que as emissões de $\mathrm{CO} 2$ geradas da queima de combustíveis fósseis sejam reduzidas e/ou eliminadas.

Para enfrentar este desafio, a assembleia geral das Organizações das Nações Unidas (ONU), em 2012, criou a iniciativa "Sustainable Energy for all", em que estabeleceu três objetivos globais a serem cumpridos até 2030: i) garantir acesso universal à eletricidade moderna; ii) duplicar a taxa global de melhorias na eficiência energética; e iii) aumentar a quantidade de energias renováveis no mix de energia global (WORLDBANK, 2017).

Neste sentido, as 50 maiores economias produziram, juntas, 77.507 TWh de energia a partir de fontes renováveis de 1990 a 2015. A Tabela 1 apresenta a produção de energia total de cada país. Estados Unidos e China correspondem a aproximadamente $43 \%$ da produção de energia elétrica dentre as 50 maiores economias. Esses países ainda são responsáveis por quase metade da produção de energias a partir de fontes não renováveis. Apesar de esses também representarem aproximadamente um terço da produção de energia renovável das 50 maiores economias, em termos relativos, essas fontes correspondem a apenas $10 \%$ e $18 \%$ na matriz elétrica dos EUA e China, respectivamente. Já em países como Brasil e Canadá, entre 1990 e 2015, a produção de energia elétrica por fontes renováveis corresponderam a $62 \%$ e $86 \%$, respectivamente. A dependência da produção elétrica por fontes não renováveis é acompanhada pelo grande volume de emissões de CO2. Por exemplo, China e EUA correspondem a $45 \%$ das emissões, dentre as 50 maiores economias. 


\begin{tabular}{llllll}
\hline & Total & Produção de Energia (\%) & Fóssil & Renovável & Emissões CO2 (Mton) \\
\hline Estados Unidos & $104.013,49$ & 26,37 & $93.325,27$ & $10.688,22$ & $141.272,11$ \\
China & $64.688,03$ & 16,40 & $52.542,64$ & $12.145,39$ & $137.872,20$ \\
Japão & $27.697,20$ & 7,02 & $24.905,64$ & $2.791,56$ & $31.195,60$ \\
Rússia & $25.065,56$ & 6,36 & $20.683,73$ & $4.381,84$ & $41.714,40$ \\
Índia & $17.913,81$ & 4,54 & $15.042,06$ & $2.871,76$ & $31.009,10$ \\
Canadá & $15.669,09$ & 3,97 & $5.973,95$ & $9.695,14$ & $13.132,10$ \\
Alemanha & $15.377,05$ & 3,90 & $13.599,90$ & $1.777,15$ & $22.002,00$ \\
França & $12.490,01$ & 3,17 & $10.611,17$ & $1.878,84$ & $9.492,70$ \\
Brasil & $10.056,52$ & 2,55 & $1.383,08$ & $8.673,44$ & $8.568,00$ \\
Reino Unido & $9.435,06$ & 2,39 & $8.902,83$ & 532,23 & $14.232,30$ \\
Todos outros países & $9.2011,99$ & 23,33 & $69.939,96$ & $22.072,03$ & $166.267,57$ \\
\hline Total & $\mathbf{3 9 4 . 4 1 7 , 8 1}$ & $\mathbf{1 0 0 , 0 0}$ & $\mathbf{3 1 6 . 9 1 0 , 2 1}$ & $\mathbf{7 7 . 5 0 7 , 6 0}$ & $\mathbf{6 1 4 . 8 6 8 , 3 8}$ \\
\hline
\end{tabular}

Tabela 01 - Produção de energia dos 50 países com maior PIB (TWh) 1990-2015

Fonte: Da pesquisa.

A China, em 2005, ultrapassou os EUA em emissão, sendo o segundo maior emissor de $\mathrm{CO} 2$ no mundo. No entanto, a China comprometeu-se, em 2014, a limitar as emissões de $\mathrm{CO} 2$ até 2030, e tem investido em fontes renováveis como eólica e solar fotovoltaica (CUI et al., 2018). Apesar disso, em 2015 respondeu por 30,7\% do total de emissões de $\mathrm{CO} 2$ do mundo, e quase duplicou as emissões dos Estados Unidos, como mostra a Figura 1.

No Japão, Rússia, Índia, Alemanha, França e Reino Unido, a produção de energia é predominantemente fóssil. No Brasil, embora a produção de energia seja majoritariamente renovável, as emissões de gases de efeito estufa se mantiveram praticamente iguais nos últimos cinco anos, devido ao desmatamento na Amazônia e do Cerrado (OBSERVATÓRIO, 2018). No Canadá, as emissões variam em função de fatores econômicos. Regiões onde a economia é baseada em serviços tendem a ter níveis mais baixos de emissão do que nas regiões que dependem da extração de recursos.

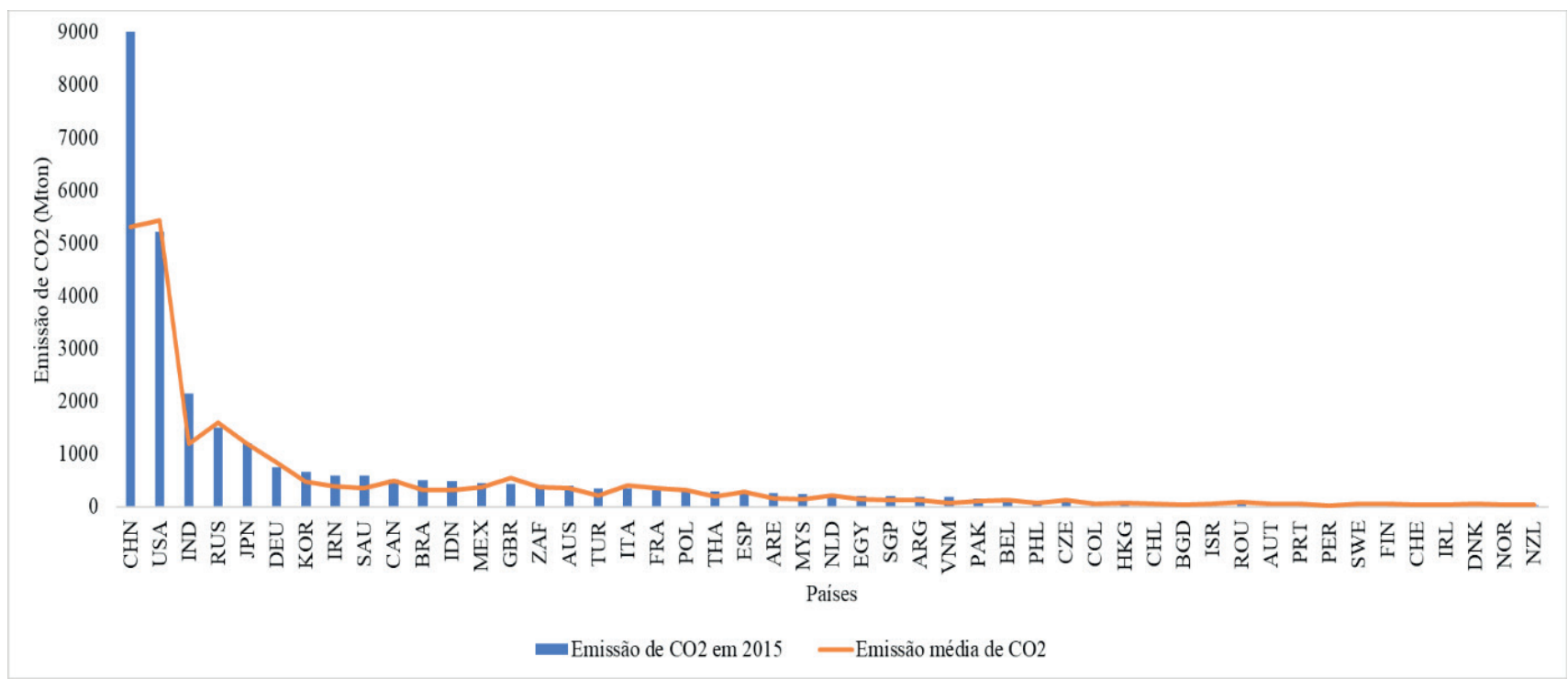

Figura 01 - Emissões de C02 (Mton) das 50 maiores economias do mundo em 2015 Fonte: Da pequisa.

\subsection{PROCEDIMENTOS METODOLÓGICOS}

Na busca pela resolução do objetivo proposto, a pesquisa foi dividida em três etapas, conforme Figura 2. Na primeira etapa, para verificar a relação entre PIB e consumo de energia, foi realizada uma correlação de Pearson entre as variáveis PIB per capita (US\$) e consumo de energia per capita (kWh). A segunda etapa foi realizada por meio de uma correlação de Pearson entre as variáveis emissão de CO2 per capita (Mton) e participação de energias renováveis na matriz elétrica. 


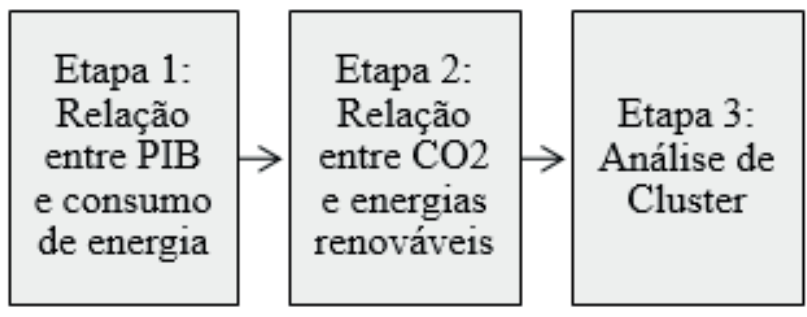

Figura 02 - Etapas realizadas na pesquisa Fonte: Da pesquisa.

Na terceira etapa, para verificar o perfil dos países que possuem similaridades, ao longo do tempo, na participação de energias renováveis em sua matriz elétrica, foi realizada uma Análise de Cluster, pelo método Ward. Para isso, foi utilizado o pacote readx1 com o software $\mathrm{R}$.
Os dados referentes às variáveis PIB per capita, consumo de energia per capita, emissão de CO2 per capita e de participação de energias renováveis na matriz elétrica foram coletados no portal eletrônico de dados abertos (WORLDBANK, 2019), compreendendo os anos de 1990 a 2015 para a participação de energia renovável e de 1990 a 2014 para as outras.

\section{RESULTADOS E DISCUSSÃO}

Para verificar relação entre PIB per capita e consumo de energia per capita, foi realizada uma correlação entre essas duas variáveis, por ano (Tabela 2). Os resultados encontrados mostram que, ao longo do tempo, os países que apresentaram um PIB per capita crescente estão acompanhados por um maior consumo de energia.

\begin{tabular}{llllll}
\hline Ano & Coeficiente de Pearson & Ano & Coeficiente de Pearson & Ano & Coeficiente de Pearson \\
\hline 1990 & 0,54 & 1999 & 0,69 & 2008 & 0,80 \\
1991 & 0,53 & 2000 & 0,71 & 2009 & 0,80 \\
1992 & 0,54 & 2001 & 0,72 & 2010 & 0,78 \\
1993 & 0,57 & 2002 & 0,73 & 2011 & 0,78 \\
1994 & 0,58 & 2003 & 0,74 & 2012 & 0,78 \\
1995 & 0,59 & 2004 & 0,73 & 2013 & 0,78 \\
1996 & 0,61 & 2005 & 0,76 & 2014 & 0,77 \\
1997 & 0,62 & 2006 & 0,77 & & \\
1998 & 0,65 & 2007 & 0,77 & & \\
\hline
\end{tabular}

Tabela 02 - Correlação de PIB per capita e consumo de energia per capita Fonte: Da pesquisa.

Apesar do crescente investimento em eficiência energética, não há indícios de desassociação entre crescimento econômico e consumo de energia. O gráfico de dispersão, apresentado na Figura 3, mostra a correlação do PIB per capita com consumo de energia per capita, em 2014, evidenciando uma tendência linear. Pode-se verificar que o consumo de energia de um país está relacionado com o crescimento econômico.

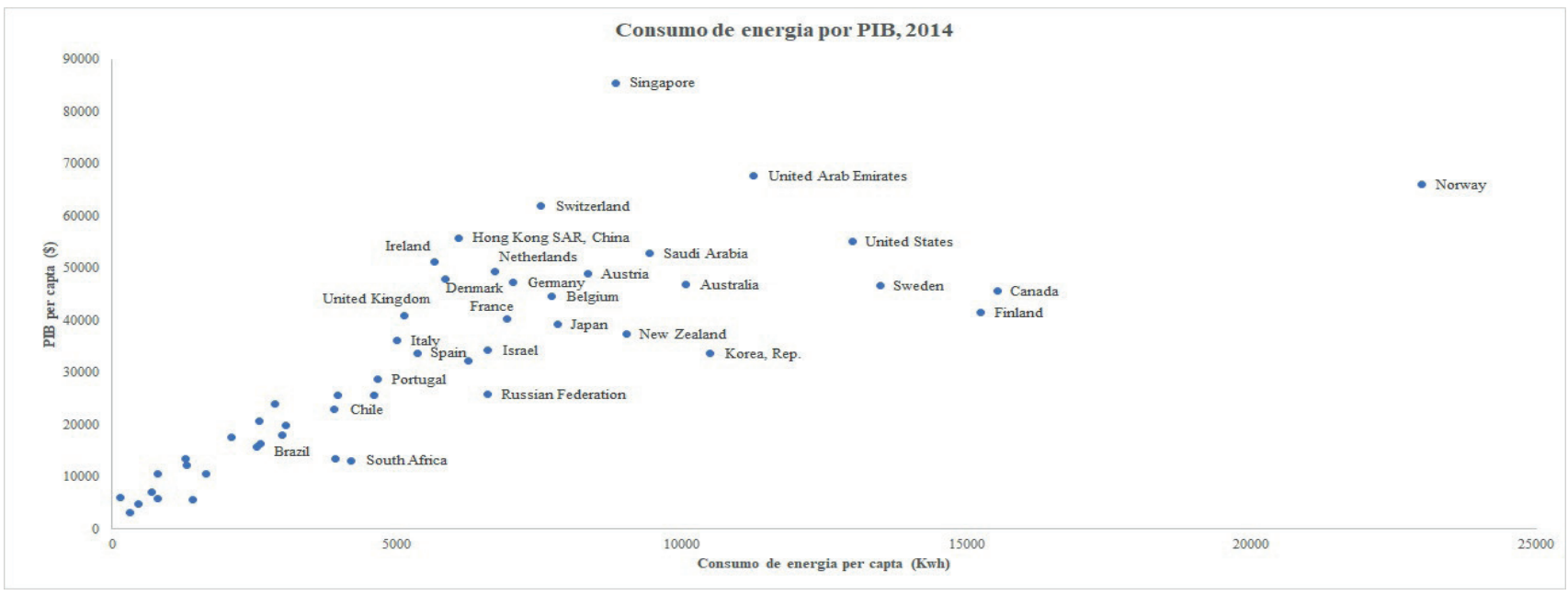

Figura 03 - Relação entre consumo de energia per capita e PIB per capita em 2014 Fonte: Da pesquisa. 
No entanto, alguns países destoam. A Noruega, por exemplo, possui o maior consumo per capita de energia, devido, principalmente, a sua exploração e exportação de petróleo e gás natural. Já Singapura tem o maior PIB per capita e uma economia baseada na indústria de tecnologia, contudo, é um país que possui forte dependência de importação de energia elétrica, bem como, de alimentos e matéria-prima.

Nos últimos anos, apesar de grandes potências econômicas terem aumentado seu consumo de energia per capita, essas nações vêm ampliando os investimentos em fontes renováveis para produzir energia, incentivadas pelos acordos internacionais e pressão da sociedade, com o objetivo de reduzir a emissão de $\mathrm{CO} 2$.

Para verificar essa relação, de emissões de $\mathrm{CO} 2$ com participação de energias renováveis na matriz elétrica, calculou-se a correlação entre a participação na produção de energias renováveis na matriz elétrica com emissões de $\mathrm{CO} 2$ per capita dos 50 países com maior PIB, por ano (Tabela 3).

\begin{tabular}{llllll}
\hline Ano & Coeficiente de Pearson & Ano & Coeficiente de Pearson & Ano & Coeficiente de Pearson \\
\hline 1990 & $-0,36$ & 1999 & $-0,32$ & 2008 & $-0,24$ \\
1991 & $-0,39$ & 2000 & $-0,31$ & 2009 & $-0,24$ \\
1992 & $-0,40$ & 2001 & $-0,33$ & 2010 & $-0,24$ \\
1993 & $-0,39$ & 2002 & $-0,32$ & 2011 & $-0,26$ \\
1994 & $-0,39$ & 2003 & $-0,30$ & 2012 & $-0,24$ \\
1995 & $-0,37$ & 2004 & $-0,28$ & 2013 & $-0,22$ \\
1996 & $-0,39$ & 2005 & $-0,28$ & 2014 & $-0,26$ \\
1997 & $-0,34$ & 2006 & $-0,29$ & & \\
1998 & $-0,32$ & 2007 & $-0,25$ & & \\
\hline
\end{tabular}

Tabela 03 - Correlação entre participação na produção de energia renovável e emissões de $\mathrm{C0} 2$ per capita

Fonte: Da pesquisa.

Observa-se que a correlação apresentada é negativa em todos os anos. Mesmo não sendo uma correlação forte, indica que países que possuem maior participação de ER em sua matriz elétrica, tendem a emitir menos $\mathrm{CO} 2$.

Somado aos resultados obtidos na análise de correlação, ao observar a média de emissão de $\mathrm{CO} 2$ per capita e participação de ER dos países por ano, os resultados indicam que há um aumento no uso de energias renováveis entre os países e que este aumento está acompanhado pela tendência de decrescimento nas emissões de CO2 (Figura 4).

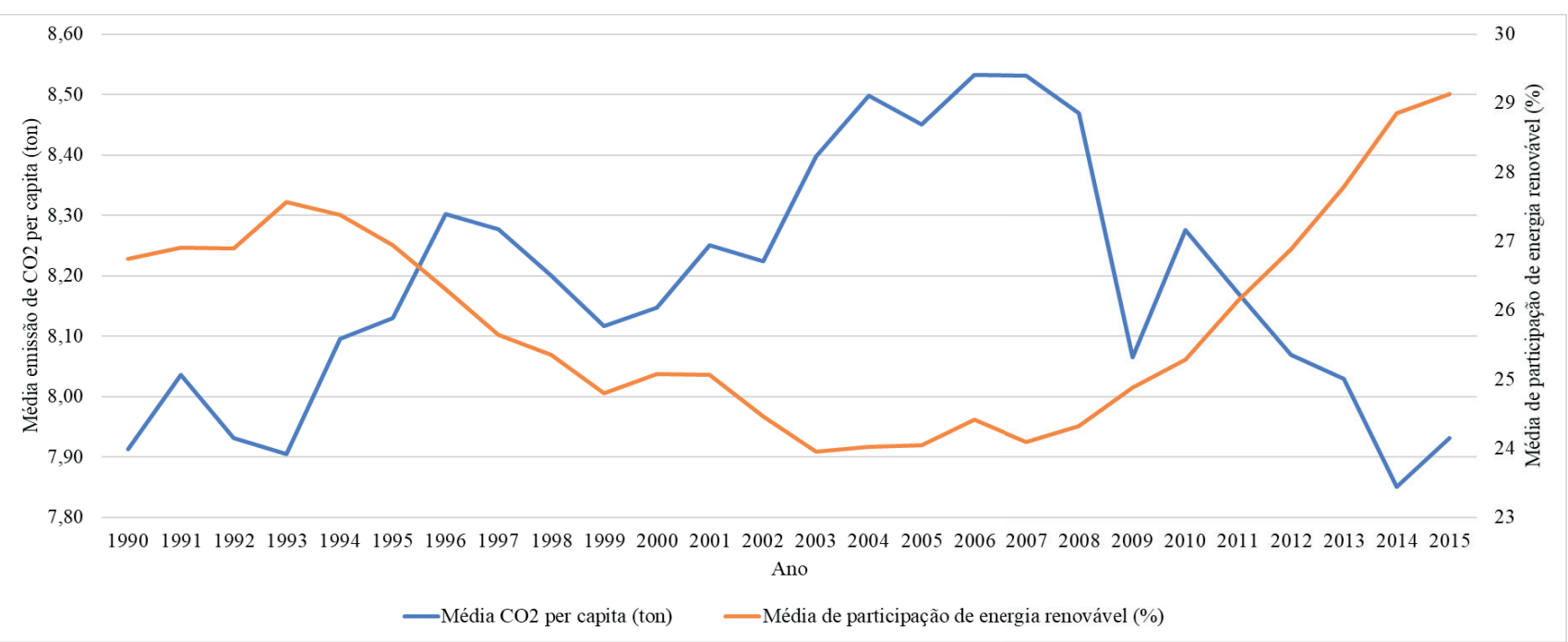

Figura 04 - Média de emissão de C02 per capita e participação de energia renovável na matriz elétrica por ano

Fonte: Da pesquisa.

Após esta análise, verificou-se que Noruega, Brasil, Colômbia, Nova Zelândia, Peru, Canadá, Suíça, Chile e Suécia, juntos, produziram mais do que a metade do montante da energia renovável. Além disso, apenas Estados Unidos e China foram responsáveis por mais de $40 \%$ do total de consumo de energia entre 1990 a 2014, dentre as 50 maiores economias. 
O consumo de energia continua aumentando, entretanto, os países vêm investindo em energias renováveis e práticas de eficiência energética. Alguns países possuem boa parte da sua matriz elétrica composta por fontes renováveis, enquanto outros são altamente dependentes de combustíveis fósseis. A fim de identificar os grupos de países que possuem participações semelhantes de ER na matriz elétrica ao longo dos anos, realizou-se uma análise de Cluster (Figura 5). Estes grupos foram organizados de forma que os países em um mesmo cluster sejam semelhantes entre si.

O primeiro grupo (cluster 1) é formado por: Chile, Vietnã, Suécia, Canadá, Suíça, Brasil, Noruega, Peru, Colômbia Áustria e Nova Zelândia.

Neste cluster, a produção de energias renováveis é de aproximadamente 28.972 TWh. Em média, ao longo dos anos, países desse cluster possuem $68 \%$ da sua matriz elétrica composta por fontes renováveis.
O segundo grupo (cluster 2) é composto por: Israel, Hong Kong, Arábia Saudita, Emirados Árabes Unidos, Coréia do Sul, Singapura, África do Sul, Bangladesh, Irã, Tailândia, Malásia, Austrália, Japão, Estados Unidos, Alemanha, Irlanda, Bélgica, Reino Unido, Holanda, República Tcheca e Polônia. Neste cluster, há uma produção de energia Hídrica, Solar, Eólica, Geotérmica, Biomassa e de Biocombustível superior a 17.801 TWh. Países desse cluster possuem, na sua matriz elétrica, em média, $5 \%$ de eletricidade proveniente de fontes renováveis.

O terceiro grupo (cluster 3) é constituído por: Turquia, Nigéria, Filipinas, Argentina, Paquistão, Portugal, Finlândia, Romênia, República Árabe do Egito, México, China, Federação Russa, França, Índia, Indonésia, Dinamarca, Itália e Espanha. A produção de energias renováveis neste cluster é de aproximadamente 30.733 TWh. Ao longo dos anos, a média de participação de energias renováveis na matriz elétrica destes países é de $24 \%$.

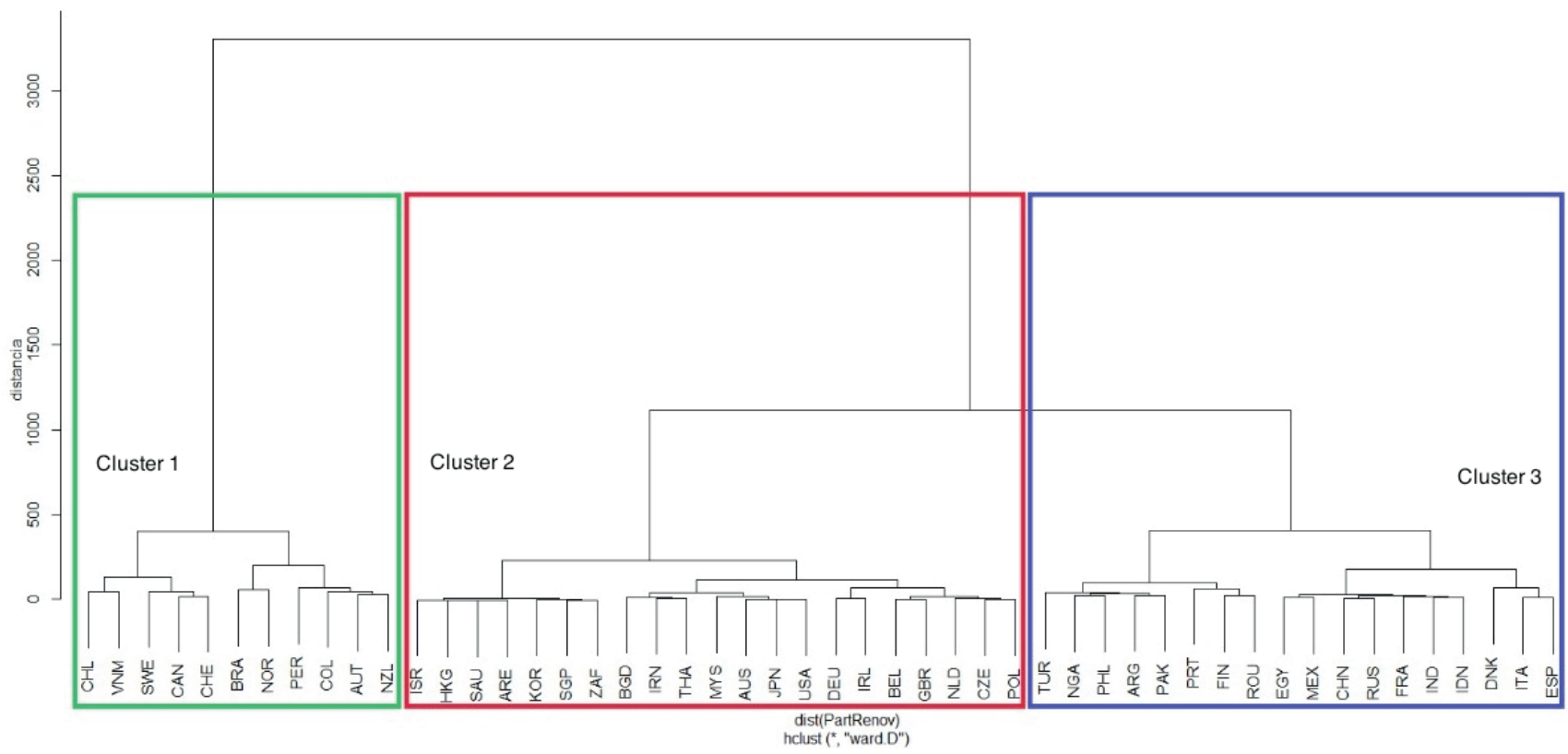

Figura 05 - Dendograma para fontes de energias renováveis Fonte: Da pesquisa.

No primeiro cluster, alguns países têm uma maior produção de energia a partir de fontes hidrelétricas, eólica e geotérmica/biomassa do que no restante dos países pertencentes a este grupo. Os países desse cluster são os que mais possuem na composição de sua matriz elétrica as energias renováveis, mas são altamente dependentes de usinas hidrelétricas.

No cluster 2, seis países se destacam, três países pela baixa participação na produção de energias renováveis, nomeadamente Hong Kong, Arábia Saudita e Emirados Árabes Unidos. Hong Kong e Emirados Árabes Unidos têm uma pequena produção de energia geotérmica/biomassa, solar e eólica, e a Arábia Saudita, a partir de 2012, passou a investir em energia solar. Já os Estados Unidos se destacam pela produção de energia hidrelétrica, geotérmica/biomassa e eólica, o Japão com a produção de energia hidrelétrica e a Alemanha com energia eólica.

No terceiro cluster, também seis países se destacam, são eles, a China, com a produção de energia hidrelétrica, eólica e geotérmica/biomassa, Rússia e Índia com hidrelétrica, França e Espanha com a produção de energia hidrelétrica e eólica e a Itália com hidrelétrica e geotérmica/ biomassa. A Figura 6 apresenta a média de participação de energias renováveis na matriz elétrica das 50 maiores economias de 1990 a 2015. 


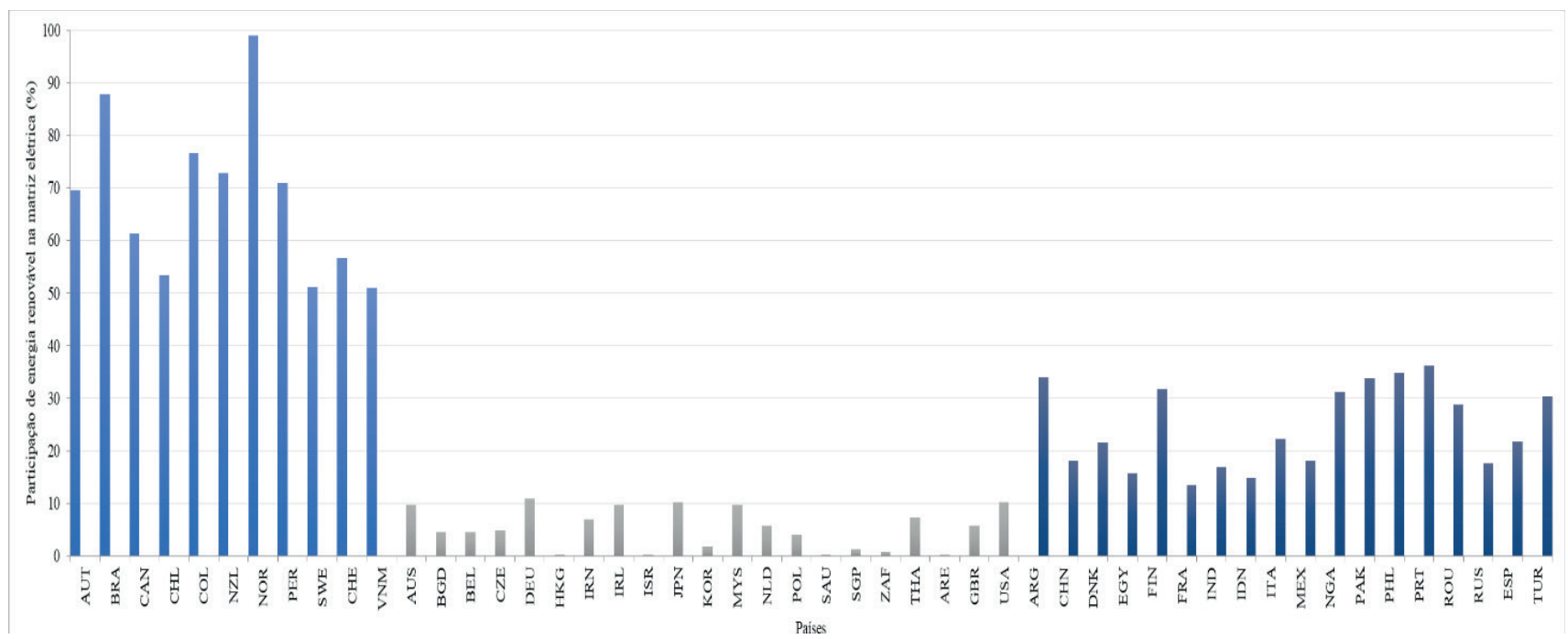

Figura 06 - Média de participação de energias renováveis na matriz elétrica das 50 maiores economias de 1990 a 2015 Fonte: Da pesquisa.

Pela Figura 6, fica evidente a diferença entre os três clusters no que diz respeito à participação de ER em suas respectivas matrizes elétricas. A Noruega produziu aproximadamente $99 \%$ da geração total de eletricidade com energias renováveis, cerca de 128 TWh de energia renovável por ano. A Dinamarca é o país com maior intensificação de energias renováveis, no período entre 2009 a 2015 apresentou um aumento superior a 37\%.

Os Estados Unidos, Índia e Bélgica produziram 13\%, $15 \%$ e $20 \%$, respectivamente, do total da eletricidade produzida com energias renováveis em 2015, inferior à média mundial de aproximadamente $24 \%$. Países da América do Sul (Brasil, Colômbia e Peru) também se destacam na produção de eletricidade por energias renováveis com uma produção de ER entre $52 \%$ e $75 \%$.

A China fez grandes avanços na área de tecnologias renováveis, com destaque para a energia eólica, biomassa e solar, com investimentos de aproximadamente $103 \mathrm{bi}$ Ihões de dólares em 2015 (UNIDO, 2016), desde 2012 a participação de ER na matriz elétrica vem aumentando $1 \%$ ao ano. No entanto, a China ainda é líder em emissões totais de $\mathrm{CO} 2$, produzindo 4,3 vezes mais combustíveis fósseis do que os renováveis. Os Estados Unidos crescem a passos lentos sua participação de ER na matriz elétrica $(0,27 \%$ de 2014 a 2015) e permanecem como líderes em emissões acumuladas de $\mathrm{CO} 2$ per capita ao ano, sendo os maiores responsáveis pelo aumento da concentração de carbono e, consequentemente, pelas mudanças climáticas.

\section{CONCLUSÃO}

Esta pesquisa teve como objetivo investigar a relação entre o PIB, consumo de energia, participação de energias renováveis e as emissões de $\mathrm{CO} 2$ per capita das 50 maiores economias do mundo durante o período de 1990 a 2015.

Usando o coeficiente de correlação de Pearson, os resultados mostraram uma correlação alta para o PIB per capita e consumo de energia, como esperado. No entanto, acredita-se que não há uma relação direta entre as variáveis, mas há um fator moderador que leva a esse resultado. Países industrializados, por exemplo, tendem a demandar mais consumo de energia, apresentando também um maior PIB. A indústria é responsável por um consumo de energia expressivo, mas vem investindo em práticas de eficiência energética.

Os resultados mostram também que não há uma correlação forte para as emissões de $\mathrm{CO} 2$ e uso de energias renováveis, evidenciando que há outras variáveis envolvidas que influenciam nas emissões, como por exemplo o desmatamento, atividades industriais como a metalurgia, a mineração e as atividades com o manejo de rebanhos bovinos.

Mesmo com o crescente investimento em energia renovável, as emissões de $\mathrm{CO} 2$ continuam aumentando, pois ainda há dependência da produção de eletricidade por fontes não renováveis. Por exemplo, a China nos últimos dois anos aumentou a produção de eletricidade por termelétricas movidas a carvão.

Conclui-se que as energias renováveis desempenham um papel importante na redução das emissões de dióxido de carbono, porém se limitar a isso não é suficiente para reduzir a emissão de $\mathrm{CO} 2$. É preciso considerar outras variáveis, como as mencionadas.

A análise de cluster evidenciou que há diferença na produção de energia renovável entre os países e mostrou que países como a Suíça, Noruega, Brasil, Canadá possuem 
o sistema elétrico mais renovável, baseados principalmente em usinas hidrelétrica, eólica e geotérmica/biomassa. $\mathrm{O}$ segundo cluster é composto por países que relativamente não produzem muita energia renovável. Já o terceiro cluster é composto por países que produzem bastante energia renovável, mas ao mesmo tempo dependem muito de combustíveis fósseis, como a China, Índia, Rússia e França.

Esta pesquisa contribui ao demonstrar a importância em investir em energias renováveis, porém apenas isso não é suficiente para reduzir a emissão de $\mathrm{CO} 2$. É necessário políticas governamentais que almejem práticas mais sustentáveis na geração de energia. Embora grande parte do setor de energia renovável tenha se beneficiado das políticas governamentais, os países devem criar condições para cumprir as metas dos acordos ambientais.

Como recomendação para trabalhos futuros, sugere-se verificar quais outras variáveis estão relacionadas com a emissão de $\mathrm{CO} 2$ e verificar, quantitativamente, o impacto dessas variáveis na emissão de $\mathrm{CO} 2$.

\section{REFERÊNCIAS}

\section{ABNT - ASSOCIAÇÃO BRASILEIRA DE NORMAS}

ADAMS, S.; NSIAH, C. Reducing carbon dioxide emissions; Does renewable energy matter? Science of The Total Environment, v. 693, p. 133288, 2019. ISSN 0048-9697.

AHMAN, M.; NILSSON, L. J.; JOHANSSON, B. Global climate policy and deep decarbonization of energy-intensive industries. Climate Policy, v. 17, n. 5, p. 634649, 2017. ISSN 1469-3062.

BANK, W. "Global Tracking Framework 2017: Progress Towards Sustainable Energy" (April), World Bank, Washington, DC. Doi: 10.1596/978-1-4648-1084-8 License: Creative Commons Attribution CC BY 3.0 IGO. 2017. Disponível em: < https://www.worldbank. org/en/topic/energy/publication/global-tracking-framework-2017>.

World Bank Open Data. World Bank

Publications, 2019.

BROZYNA, J. et al. Classification of Renewable Sources of Electricity in the Context of Sustainable Development of the New EU Member States. Energies, v. 12, n. 12, p. 22, Jun 2019. ISSN 1996-1073.

CUI, H.; ZHAO, T.; WU, R. CO2 emissions from China's power industry: Policy implications from both macro and micro perspectives. Journal of Cleaner Production, v. 200, p. 746-755, 2018. ISSN 09596526 (ISSN).

IPCC. Climate Change 2014: Mitigation of Climate
Change: Working Group III Contribution to the Fifth Assessment Report of the Intergovernmental Panel on Climate Change. Cambridge University Press, 2014a. ISBN 110705821X.

Climate Change 2014: Synthesis Report. Contribution of Working Groups I, II and III to the Fifth Assessment

Report of the Intergovernmental Panel on Climate Change. [Core Writing Team, R.K. Pachauri and L.A. Meyer (Eds.)].

Geneva: IPCC., 2014b.

KERN, F.; ROGGE, K. S. The pace of governed energy transitions: Agency, international dynamics and the global Paris agreement accelerating decarbonisation processes? Energy Research \& Social Science, v. 22, p. 13-17, 2016. ISSN 2214-6296.

LIN, B.; AHMAD, I. Analysis of energy related carbon dioxide emission and reduction potential in Pakistan. Journal of cleaner production, v. 143, p. 278-287, 2017. ISSN 0959-6526.

LIN, B. Q.; RAZA, M. Y. Analysis of energy related CO2 emissions in Pakistan. Journal of Cleaner Production, v. 219, p. 981-993, May 2019. ISSN 0959-6526.

MEROUEH, L.; CHEN, G. Thermal energy storage radiatively coupled to a supercritical Rankine cycle for electric grid support. Renewable Energy, v. 145, p. 604621, 2020. ISSN 0960-1481.

OBSERVATÓRIO, D. C. Emissões do Brasil caem 2,3\% em 2017. Brasília: Observatório do Clima, 2018.

SAMPEDRO, J.; ARTO, I.; GONZÁLEZ-EGUINO, M. Implications of switching fossil fuel subsidies to solar: A case study for the European Union. Sustainability, v. 10, n. 1, p. 50, 2017.

SCHELLNHUBER, H.-J. et al. Final report of the HighLevel Panel of the European Decarbonisation Pathways Initiative. 2018.

UNIDO. FUTURO PROMISSOR: INVESTIMENTO GLOBAL EM ENERGIA RENOVÁVEL É MAIS QUE O DOBRO DO INVESTIMENTO EM CARVÃO E GÁS. Observatorio de Energía Renovable Para América Latina y el Caribe, 2016.

\section{AGRADECIMENTOS}

Os autores agradecem à Coordenação de Aperfeiçoamento de Pessoal de Nível Superior (CAPES) e ao Conselho Nacional de Desenvolvimento Científico e Tecnológico (CNPq), pelo financiamento da pesquisa. 


\section{AUTORES}

ORCID: https://orcid.org/0000-0002-0490-9233

MATHEUS FERNANDO MORO, M.Sc.| Universidade Federal de Santa Catarina (UFSC)| Programa de Pós-graduação em Engenharia de Produção (PPGEP) | Florianópolis, SC -Brasil | Correspondência para: (Rua Capitão Américo 29, Ap. 04 - Córrego Grande, Florianópolis-SC, 88040-060) | E-mail: morosmi@hotmail.com

ORCID: https://orcid.org/0000-0003-1640-8935

ANNY KEY DE SOUZA MENDONÇA, Dra. | Universidade Federal de Santa Catarina (UFSC) | Programa de Pós-Graduação em Engenharia de Produção (PPGEP) | Florianópolis, SC - Brasil | Correspondência para: (Servidão do Porto, 165, Lagoa da Conceição, Florianópolis-SC, )

ORCID: https://orcid.org/0000-0003-4505-1728

GABRIEL DE ANDRADE CONRADI BARNI, M.Sc. | Universidade Federal de Santa Catarina (UFSC) | Programa de PósGraduação em Engenharia de Produção (PPGEP) | Florianópolis, SC - Brasil | Correspondência para: (Rua Bernardo Halfeld, 185, bloco C, apartamento 106 - Nossa Senhora do Rosário, São José, SC, 88110-695) | E-mail: barni.gabriel@hotmail.com

ORCID: https://orcid.org/0000-0003-3468-7536

ANTONIO CEZAR BORNIA, Dr. | Universidade Federal de Santa Catarina (UFSC) | Programa de Pós-Graduação em Engenharia de Produção (PPGEP) | Florianópolis, SC Brasil | Correspondência para: (UFSC/CTC/EPS - CP 476 - Campus Universitário, Florianópolis, SC, 88040-900) | E-maill: cezar.bornia@ufsc.br

\section{COMO CITAR ESTE ARTIGO}

MORO, Matheus Fernando; MENDONÇA, Anny Key; BARNI, Gabriel de Andrade Conradi; BORNIA, Antonio Cezar. Transformação Global da Energia: A Participação das Energias Renováveis na Matriz Elétrica das 50 Maiores Economias. MIX Sustentável, [S.I.], v. 5, n. 4, p. xx-xx, nov. 2019. ISSN 24473073. Disponível em:<http://www.nexos.ufsc.br/index.php/ mixsustentavel>. Acesso em: dia mês. ano. doi:https:// doi.org/10.29183/2447-3073.MIX2019.v5.n4.xx-xx. 
